desired. The solution undoubtedly destroys the superficial parts of the operative field, closes the cut ends of the capillaries and lymphatic channels and apparently eliminates the danger of cancer cell implantation. In a recent case of sarcoma of the parotid the solution was applied directly to the carotid arteries and internal jugular vein; the duration of contact was too long; the vein became a brownish color and I feared that the destructive action would prove of detriment, but no untoward symptoms followed. We have used Harrington's solution in the surgical clinic at the Washington University with gratifying results. A few days ago a young man who had been struck on the lower lip with a pair of brass knuckles presented himself for treatment. Examination showed a gangrenous condition of a V-shaped portion of the lower lip. The gangrenous tissue was excised, the wound margins thoroughly cleansed with Ffarrington's solution and the parts sutured. Primary union followed. Sutures removed on fourth day.

\section{REPORT OF CASES}

CASE 1.-History-Mr. J. K., aged 57, was readmitted in Sentember, 1908. When a child he sustained a severe burn on left cheek. In January, 1908, he was struck in this region and shortly thereafter a small ulcer appeared and grew gradually larger. In May, 1908, it was as large as a silver dollar. On entrance, Dr. Drake found that the malignant mass was situated in the scar of the burn; the eye was intact. Healing did not follow excision of the growth. During the past two months the parts had become very painful and the growth markedly larger. Patient returned for excision of growth.

Examination.-This showed large, destructive growth on left cheek involving the orbital tissues and the cervical glands. General appearance of patient was very poor. Left side of face was paralyzed.

Operation.-Under ether anesthesia (preceded by morphin and atropin), a large flap was dissected from the neck, the left anterior triangle of the nerk was cleared of glands and fat, Harrington's solution yrastapplied both to the flap and to the operation wound, the latter was then sutured and the flap wrapped in gauze, and then covered with a towel, in the hands of one of the assistant. The orbital cavity was then cleaned out and the parts uched with Harrington's solution, after which the cavity was packed with gaume. After free excision of the growth on cheek and sponging the parts with Harrington's solution, the flap was sutured in position (Fig. 1). The orbital cavity was left open for $x$-ray purposes. The sutures in flap were removed on the fifth day, and the neck sutures on the seventh. Roentgen ray exposures were given every third day.

CASE 2.-History.-Mr. J. S., aged 56, admitted September 14, 1908. Four years ago he noticed a small growth on right cheek near malar eminence. Became larger and painful. Two years ago he had the growth removed, but the wound did not completely heal. During the past year the growth had been in. creasing in size and had become quite painful. Four months ago patient noticed small ulcer in middle of lower lip; this had been getting larger and would not heal.

Examination.-This was shown to be an epithelioma of Iower lip; no palpable submental glandular involvement. Over the right malar eminence was an epitheliomatous mass as large as a silver dollar; the growth was very firm and ulcerated. The orbital cavity seemed frec. The glands of neck were somewhat enlarged. The growth was movable.

Ireatment.-Under ether anesthesia (preceded by morphin and atropin) a flap was dissected up from neck, the glands together with the periglandular fat, were excised and the operation wound sponged with Harrington's solution, after which the flap was likewise treated and wrapped in gauze, and the wound closed. The carcinomatous mass was then freely ex. cised and the parts sponged with Harrington's solution, followed with saline solution. The flap was sutured in place and temporary dressings applied. After securing fresh instruments and gloves, the submental glands and periglandular fat were removed and the operation wound sponged with Harrington's solution, and then sutured. The Iip growth was then excised, the parts touched with the solution, and then sutured. Primary union followed. The illustration (Fig. 2) shows the wound five days after operation. The deep sutures were removed from cheek and neck on the eighth day.

\section{REMARKS}

I do not offer Harrington's solution as a substitute for proper surgical technic in cancer surgery, but as a valuable and efficient aid to the best possible surgical technic for the prevention of cancer cell implantation. Experiments are now in progress to determine the exact depth to which the destructive process extends when the solution is applied to a section of carcinomatous tissue for one, one and one-half, two and three minutes respectively. These results will be reported later. When the solution is applied to healthy tissue the destructive action is plainly seen.

At the present time I apply Harrington's solution to every part of the cut surface of the carcinomatous mass that is being removed; the growth is excised as rapidly and as carefully as possible, after the infected lymphatics and their periglandular tissue have been excised. After stoppage of hemorrhage in the wound the solution is applied to the entire field for one-half to one minute, depending on the character of the surface. In delicate flap operations the solution is very carefully applied. It is essential that all parts of the wound be touched with the solution. Where extensive dissections have been it is advisable to use a rubber-tissue drain. In intra-abdominal carcinoma the solution is applied to the abdominal wound after closure of peritoneum. When the extra-abdominal tumor is ulcerated Harrington's solution is applied for two minutes to the ulcerated portion.

4826 Delmar Boulevard.

\section{SOME PRINCIPLES OF CEREBRAL SURGERY *}

HARVEY CUSHING, M.D.

Associate Professor of Surgery, Johns Hopkins Hospital BALTIMORE

In the presence of an extrauterine pregnancy, of an inflamed appendix, of gallstones, of pyloric stenosis, or what you will, of the many intra-abdominal lesions so frequently encountered, how many surgeons feel less competent to recognize the condition than their colleagues who are disinclined themselves to handle scalpel and forceps? And further, would these very colleagues be willing for a moment to call the surgeon in consultation on these cases if they did not feel assured that he is as familiar as they themselves with the anatomy and physiology of the organ concerned and the morbid processes, with their complications, to which it is liable?

One of the trying responsibilities of many physicians arises from the consciousneas that they must protect their patients from the over-zealous interest of the chance operator, whose manual facility exceeds his knowledge of diseåse, an attitude almost as deplorable as that in which the trained surgeon may find himself with his opportunity to relieve slipping by, owing to

* Read in the Joint Meeting of the Section on Suryery and Anatomr and the Section on Laryngology and Otology of the American Medical Association, at the Fifty-ninth Annual Sessicn, at Chicago, June, 1908 
the procrastination of the attendant who favors surgery not at all, or as the last resort only.

Yet neither party would be willing to recall the day, not far remote indeed, when the physician selected the instruments for and directed the course of an operation so simple as a herniotomy, the "Bruchschneider" having been merely the more skilful hands for the better informed mind and superior judgment of the physician. Under this relation the advance of surgical therapy was necessarily slow, if not indeed often backward, and strides were not made in this manipulative division of therapeutics until the Hunters and the Hallers, the Bells and the Brodies, the Langenbecks and the Listers began to place a knowledge of the condition of disease as the chief asset of the surgeon-not his mere familiarity with probe and bistoury.

And yet this is the condition of things which pertains to-day in neurology; and it is putting the cart first for us surgeons to talk wisely about the technic of neurologic surgery if we know so little about the maladies toward which these measures are to be directed. Operations become dangerously safe under such circumstances, and if we do not invade this uncertain

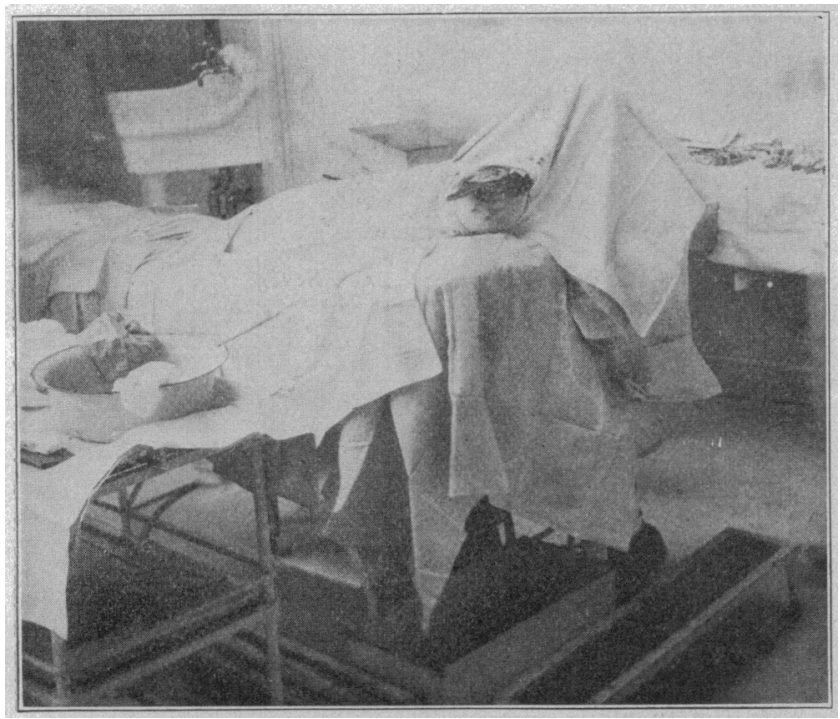

Fig. 1-Photograph taken during the course of a cranlotomy, just before elevation of an osteoplastic fiap, to show well protected field and hood for anesthetist.

field most cautiously we may be open to the same criticism not unjustly cast on the activity of certain laparotomists, likened to the inquisitive child who cuts a hole in a drum-head to see where the noise comes from.

As surgeons approaching neurologic maladies, what most of us need, therefore-a "finger and thumb" knowledge of neurology - can only be obtained with labor, patience and tears, for even the best of our schools do not as yet particularize on the relation of surgical measures to diseases of the nervous system, as they have come to do in the case of the eye and ear, of the pelvic and genitourinary organs, of the alimentary canal, the bones and joints, and what not, though it is a still more specialized form of work. Thus it is, I think, that those who look forward to a career in neurology should be instructed in matters of surgical technic-in other words, that a school of neurologists must grow up in the next generation with a general surgical training which will enable them to do their own operations. Now they can only stand by and wring their hands at the incompetency of much of the work that is being done for them by others.

After this preamble, which is indeed the most important of the things I shall have to say, I may pass to the brief consideration of the few principles which I desire to emphasize.

\section{FUNCTIONAL DISTURBANCES}

Practically all diseases, whatever they may be, have a certain superstructure of symptoms, which we choose to call functional, superimposed on those for which an

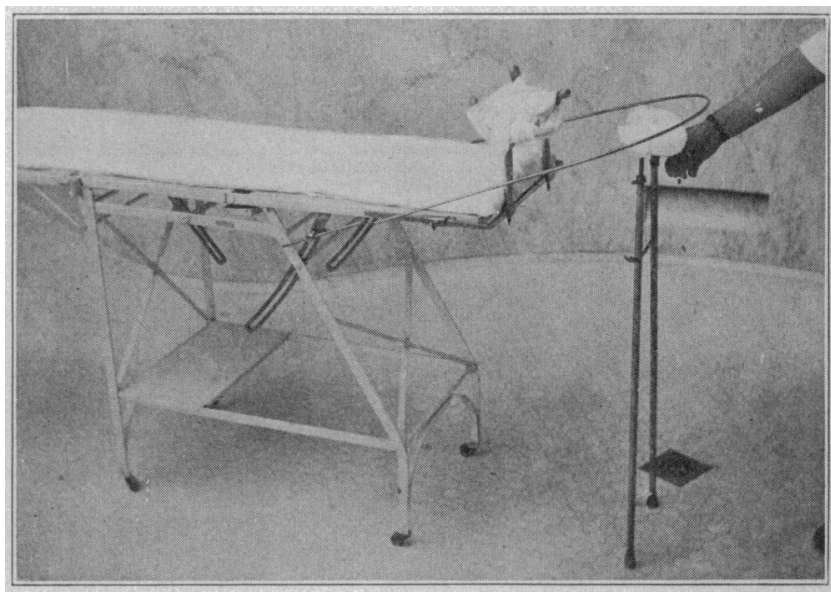

Fig. 2.- Showing table for cerebellar operations with outrigger shoulder supports, crutch for head, and hoop to support operative sheets.

actual organic lesion is clearly responsible. This superstructure may often so ove; top the basal trouble, which may actually be trifling, is to completely obscure it, and neurasthenic or psyc isthenic states result. This is especially true of lesi. . which primarily affect the nervous system itself; anu : class of patients require so much personal direction and moral control as do many of these unfortunates. .

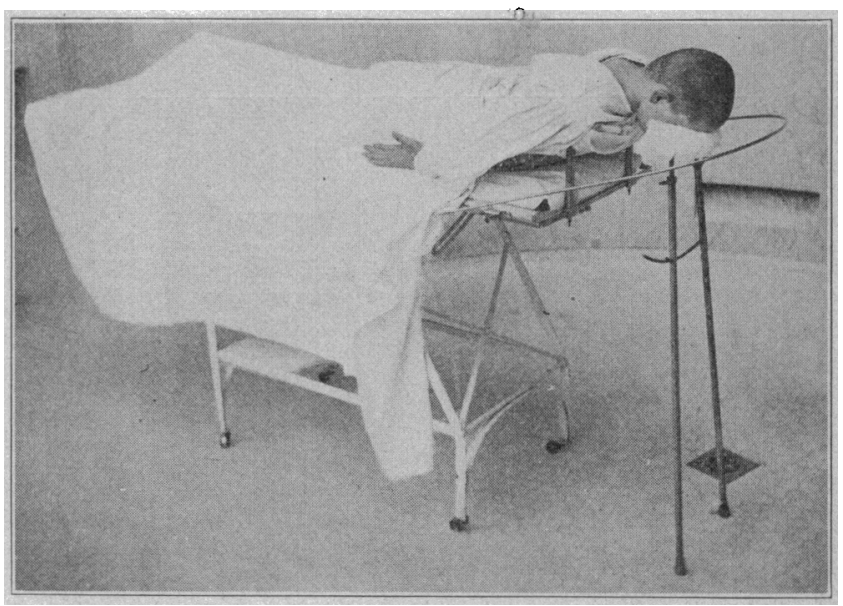

Fig. 3.- Same as Fig. 2. Patient in position before anesthesia

Oftentimes the relief of the functional element is more to be desired than the cure of the organic lesion, even if one be recognized; and it is one of the deserved criticisms of many operators that we are apt to let our patients go with their organic lesion healed-may we say cured?-but with their functional distress unabated or even accentuated. It lies within the power-indeed it is the duty-of the surgeon who takes these cases in charge, not only to remove or improve the condition of 
the underlying lesion, if that is possible, but to attend as well to these so-called neuroses, and it is for this reason, if for no other, that he must not only get intimately in touch with his patient by a history and thorough personal examination, but must also attend himself to every detail of operative preparation and after-treatment. Whether he exercises its power consciously or-as is true

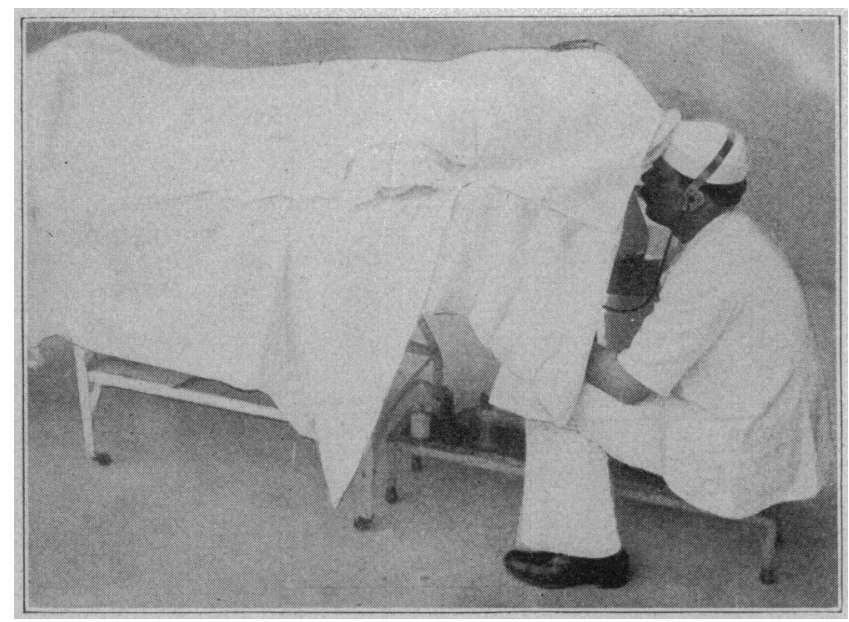

Fig. 4.--Same as Figs. 2 and 3 . Anesthetist wearing headband with receiver and tube leading from phonendoscope.

of many of the most successful therapeutists-unconsciously and as a natural gift, what has come to be "dignified" as psychotherapy must be the neurologist's constant resource, be he surgeon or otherwise.

\section{ANESTHESIA}

Among the numerous details of a cranial operation there is one thing I particularly wish to dwell on-the administration of the anesthetic ${ }^{1}$. In cranial operations in particular, not only because of the cramped field and the need of a covering for the anesthetist, but also because the cardio-respiratory centers in the medulla are often already embarrassed through pressure, anesthetization by an expert is absolutely essential. There are

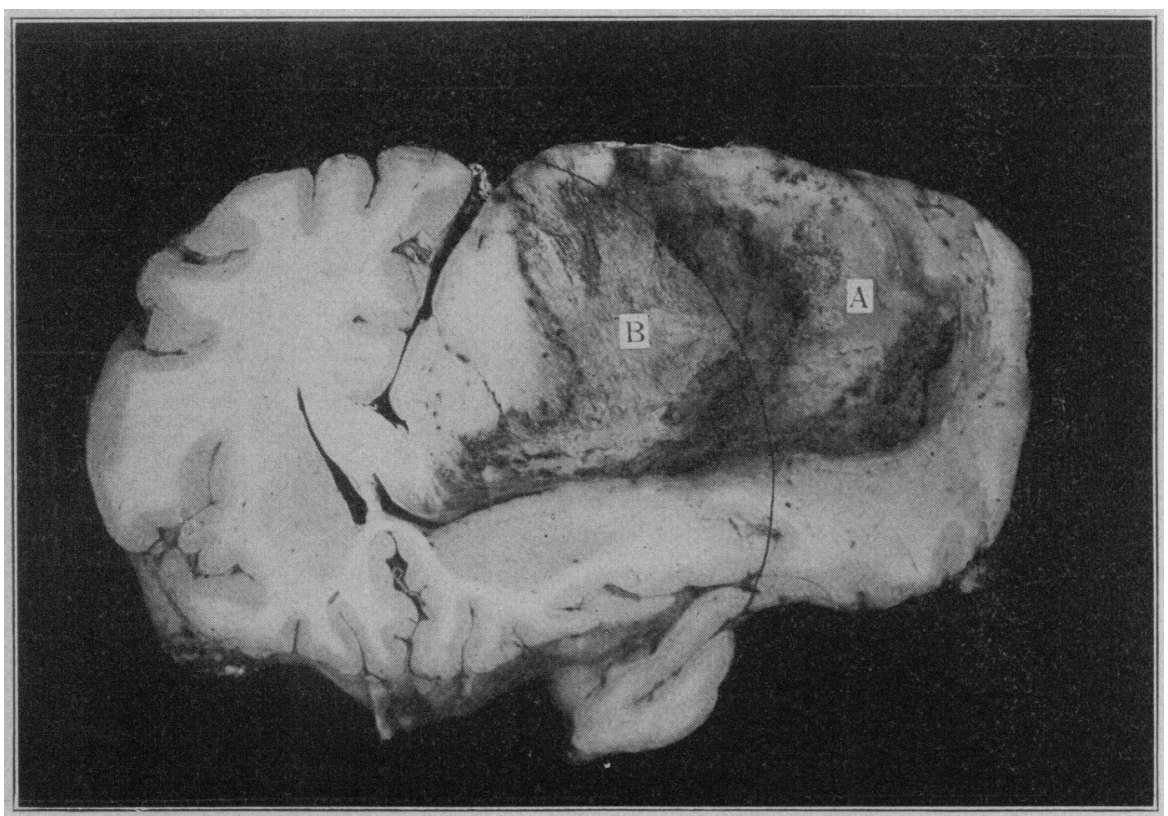

Fig. 6.-Large glioma (A) of right hemisphere leading to contralateral hemiplegia and hemianesthesia, with enormous hernia which followed exploration and decompres-
sion directly over the growth, in consequence of hemorrhage (B) into the substance of sion directly over the growth, in consequence of hemorrhage (B) into the substance trials enough for the surgeon in these cases without the added anxiety in regard to narcosis. For the past few years Dr. S. Griffith Davis, who devotes his time almost exclusively to this work, has greatly lightened these responsibilities for me by anesthetising all my neurologic patients. It is due entirely to his skill that in over three hundred cranial operations there has been a com-

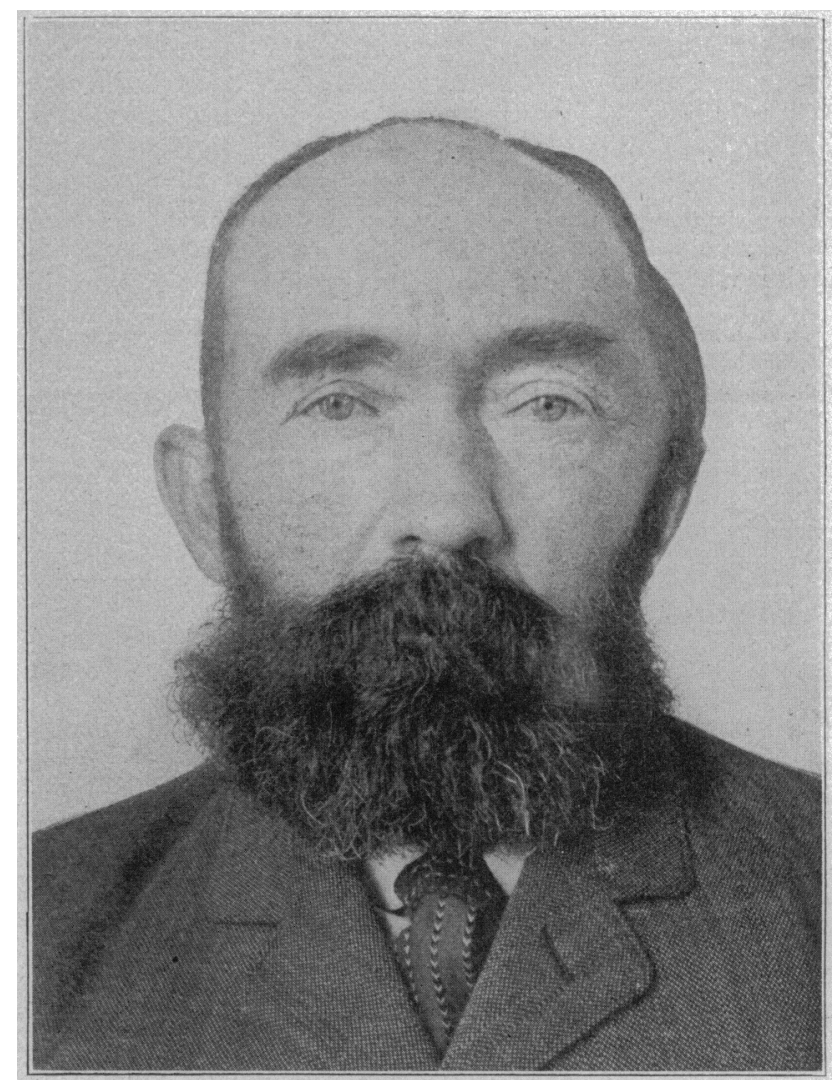

Fig. 5,-Showing fairly large left subtemporal protrusion sis months after decompression for unlocalizable growth. Patient in perfect bealth and actively engaged in his occupation as a farmer.

plete absence of the calamities usually assigned to anesthesia.

Owing to the difficulty in cranial work of shutting off the anesthetist from the operative field, many have advocated rectal or other bizarre forms of administering the various drugs employed for this purpose; but we have been so free from accidents on this score and have learned to arrange so securely the operative sheets as to make a hood which effectually conceals the anesthetist and leaves exposed only the immediate small field of operation (Fig. 1), that we have clung to the more familiar and, I think, safer method of inhalation anesthesia.

I have described elsewhere ${ }^{2}$ our invariable custom of shaving such

1. The general disregard of the risks of anesthesia, particularly in this country. has been deservedly arraigned by John B. Roberts: The Anesthesia Peril in American Hospitals, Therapeutic Gaz., February, 1908.

2. Technical Methods of Performing Certain Cranial Operations. Sur. Grn. and Obstet., March, 1908. 227. 
portion of the scalp as needs to be prepared, just before the operation; of placing the patient on the table in the most comfortable position compatible with a good operative exposure before the anesthetization is begun; and of superficially outlining the proposed incision on the scalp after its final cleansing and before the small operative field is securely and closely surrounded with the sheets and towels, which are often pinned directly into the scalp to insure against their dislodgment during the course of what may be a long operation.

The large sheet which covers the etherizer is provided with a semicircular notch cut into one side, at the angles of which are fastened tapes to be tied around the patient's head, thus securely anchoring the coverings in such a position as to expose merely the area of the incision previously scratched on the scalp.

The two alternatives to this method-(1) the shaving of the head the day before with delineation on the scalp of the cerebral fissures or of the proposed incision with an indelible pencil, or (2) the leaving of the head so exposed after the final preparation of the field that the bony landmarks can then be utilized for these determinations at the time of operation-both possess serious drawbacks.

To some, these may seem petty details, but the total freedom from infection, even as a stitch abscess, in a

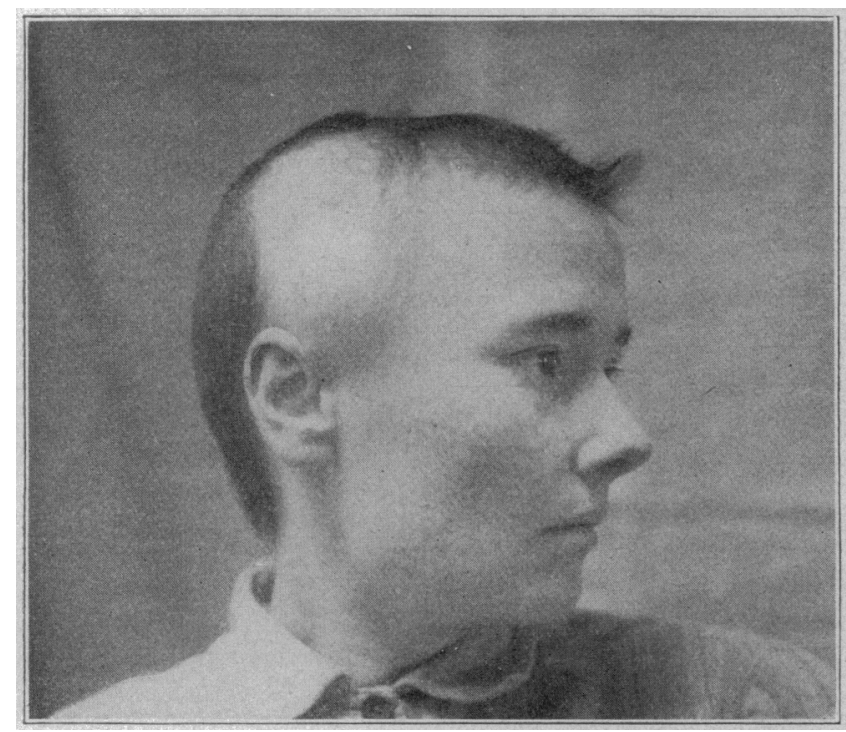

Fig. 7.-Patient with right subtemporal decompression, performed April, 1907, at a time when no recognizable focal symptoms were present. In May, 1908, a beginning loss of stereognostic perception in the left hand pointed to the position of the tumor in the right superior parietal lobe. It proved to be an encapsulated growth which was successfully removed. See Fig. 8.

series of three or four hundred craniotomies justifies the attention paid to then. ${ }^{3}$

I have already spoken of the fact that these patients, particularly in the presence of tumor, not infrequently show evidence before the operation of some respiratory embarrassment, and for this reason the administration of the anesthetic on the table in a position which assures free respiratory movements is a most essential precaution.

A special form of outrigger with head and shoulder supports (Figs. 2, 3 and 4 ) has been found neces-

3. The only cranial operation in my entire series in which the wound has become infected occurred in another city where I had been persuaded to perfot'm a decompressive operation for tumor, and where it was impossible to follow our usual routine. sary, however, only for suboccipital or high spinal operations in which a symmetrical exposure is desirable, for reasons-on the principle of dislocation-to be explained later.

I was led to adopt such a table extension owing to the respiratory difficulties which patients experienced ${ }^{4}$ when placed in a prone position without such supports, and further by the added difficulty to the anesthetist which this position otherwise engenders. Since its adoption these posterior operations, so far as position goes, have proved no more trying than those on the more accessible cranial vault.

It has been possible in my 24 cerebellar cases, largely owing to this device, to complete the operation in one sitting and thus to avoid a "two stage"

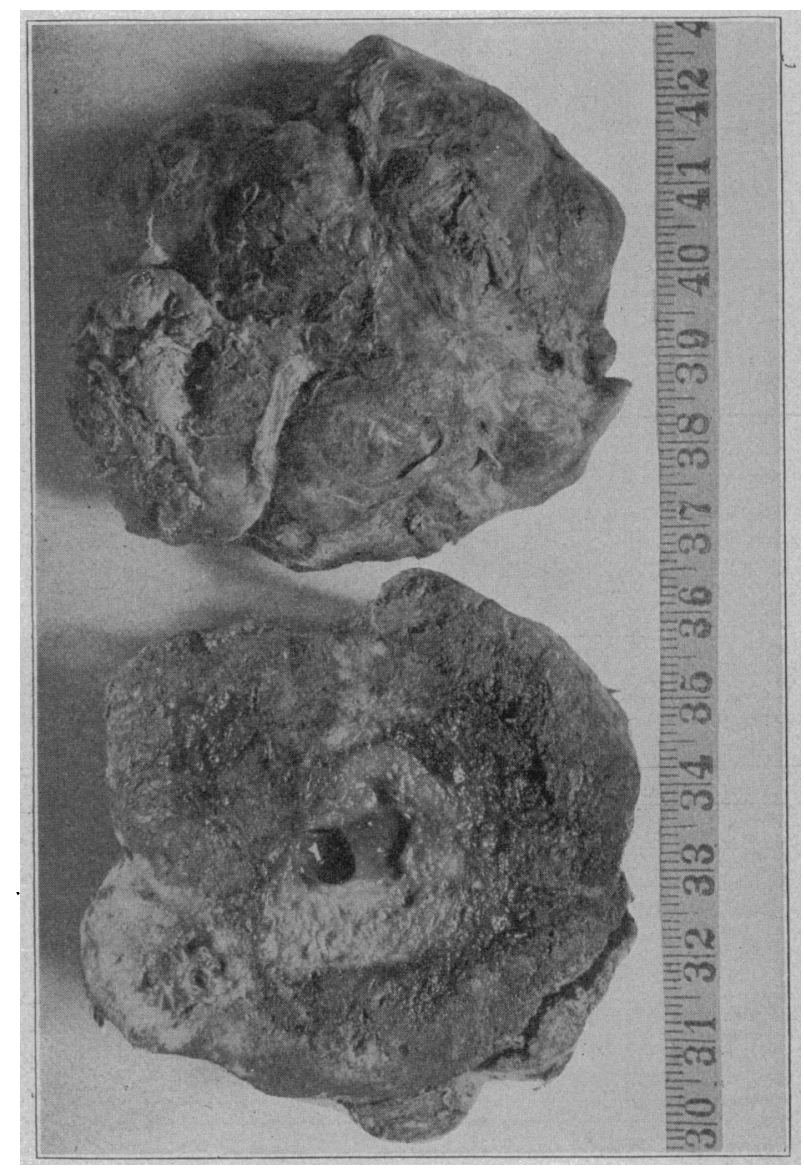

Fig. 8.-Shows (above) the external surface of the tumor removed from patient, Fig. 7 ; and (below) the median section of the growth which is beginning to undergo central cystic degeneration. (Size slightly reduced.)

performance-especially undesirable in suboccipital work.

With a patient in this prone position it is difficult for the anesthetist to gauge fully the variations in cardiac action, and during the past six months Dr. Davis has employed in these, as in all other operations indeed, a simple device, so satisfactory that we wonder why it has not long since come into general usenamely, the continuous auscultation of cardiac and respiratory rhythm during the entire course of anesthesia.

The idea arose from a practice in the Hunterian Laboratory of auscultating the heart during the production

4. My first operation for a cerebello-pontine tumor resulted in a death from inhalation pneumonia - an experience which led to the adoption of this particular form of table extension. Since its employment I have had two successful extirpations of these lateral recess growths. 
of experimental valvular lesions, and like other things has been carried from laboratory to clinic. The transmitter of a phenendoscope is secured by adhesive strips over the precordium and connects by a long tube with the anesthetist's ear, where the receiver is held by a device similar to a telephone operator's headgear (Fig. 4).

Uninterrupted information of the patient's condition
[A series of lantern slides was shown at this point, illustrating Dr. Cushing's chosen method of performing the usual osteoplastic craniotomy.-ED.]

\section{DECOMPRESSIVE MEASURES}

Adopting, as I presumed, for the first time in English the term trépanation décompressive, introduced by

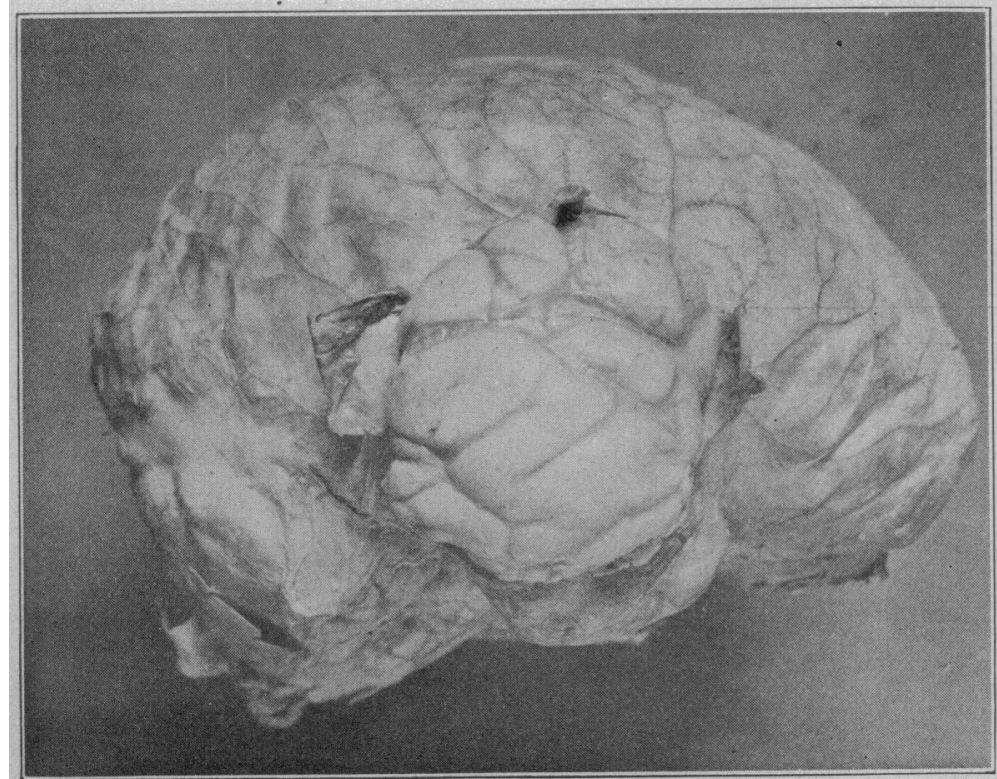

Figure 9.

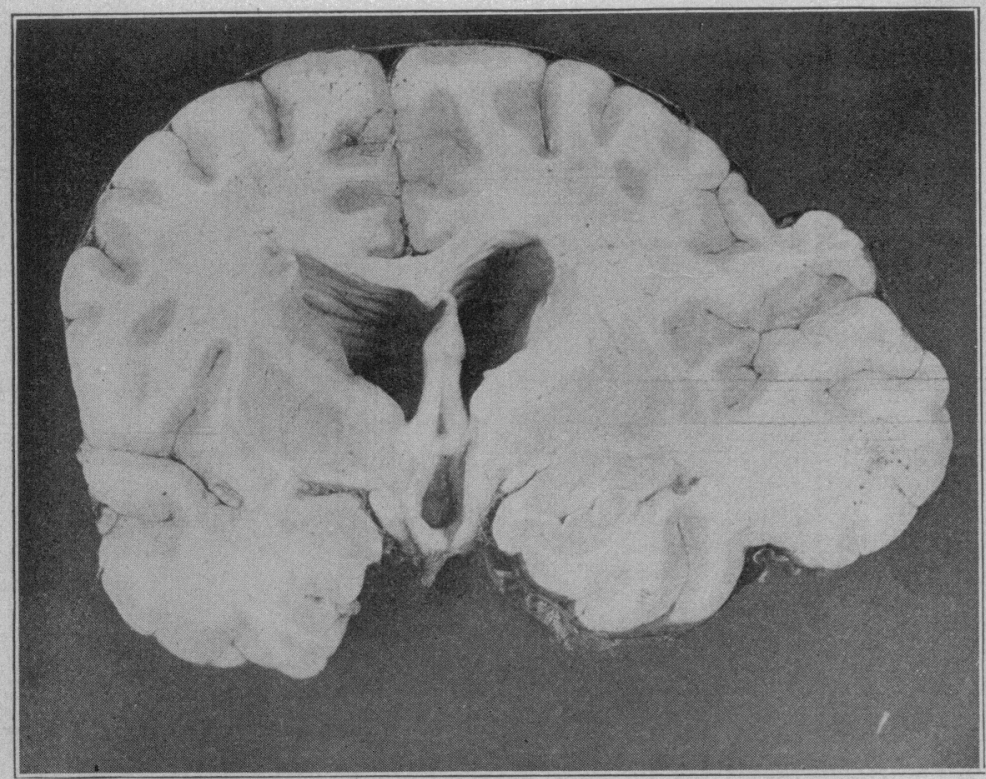

Figure 10.

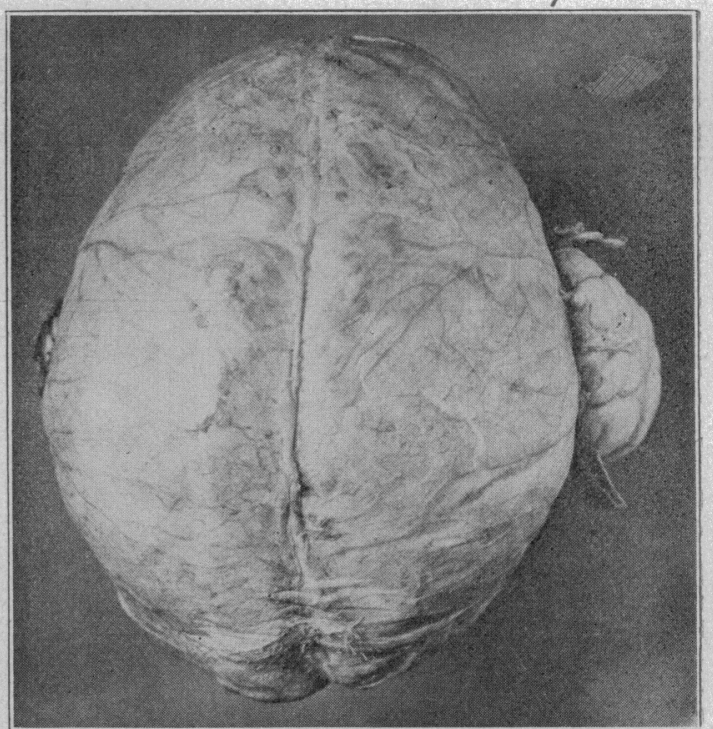

Figure 11

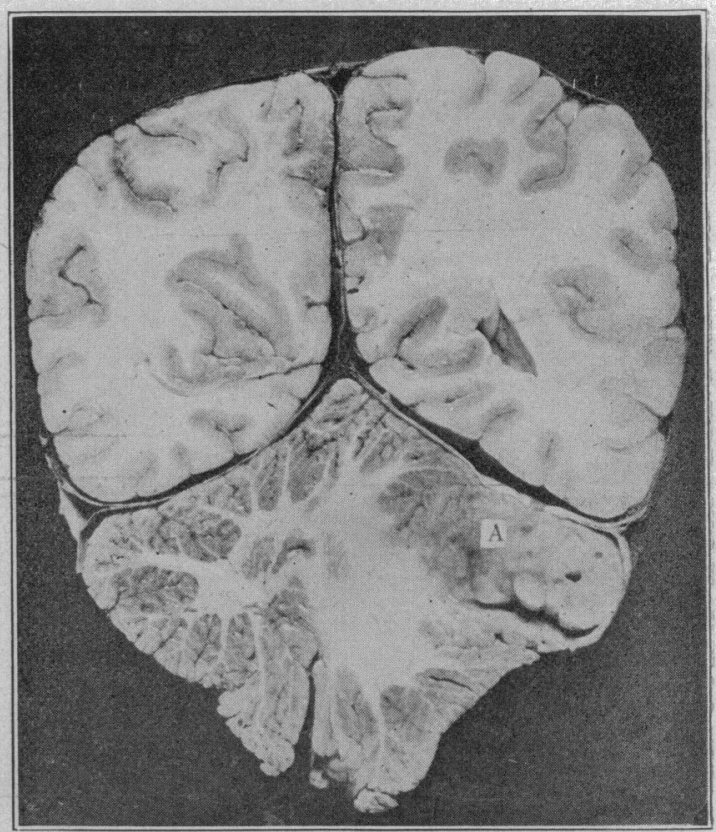

Figure 12.

Figs. 9, 10, 11 and 12.-Photographs of the brain and its enveiopes from a patient in whom a right subtemporal decompression had been performed for unlocalizable tumor. Symptoms not greatly relieved in consequence of unsuspected obstructive hydrocephalus. A month later a misgulded lumbar puncture led to a promptly fatal issue. Note in Figs. 9, 10 and 11 the situation and extent of protrusion with complete absence of cortical adhesions; the hydrocephalus in Fig. 10 ; the tumor at $\mathrm{A}$ in Fig. 12 a right cerebellar glioma.

is thus given, and the anesthetist need not disengage a hand for the occasional palpation of the pulse, which is all that he is usually expected to do. On several occasions, by the prompt appreciation of change in heartbeat or respiration thus acquired, it has been possible to avert what otherwise might have been surgical disasters, owing to the immediate warning which led to the cessation of certain disturbing manipulations.
Jaboulay $^{5}$ and used later by Broca and Maubrac ${ }^{6}$, together with suggestions offered chiefly by Horsley and Sænger, I described, ${ }^{7}$ in October, 1905, a method of de-

5. La trépanation decompressive (la mobilizaton de la voute du crane), Lyon Médical, 1896, Ixxxiil. 73 .

6. Traitement chirurgical palliatif des tumeurs cérébrales, Arch. Général de Méd., 1906, i, 129.

7. The Establishment of Cerebral Hernia as a Decompressive Measure for Inaccessible Brain Tumors, Sur., Gyn. and Obstet. October, 1905, 297 . 
compression for brain tumor by establishing a defect of bone and dura in the subtemporal region where a socalled mute area of the brain might protrude and yet receive a certain protection through the overlying muscle and fascia.

Subsequent to the appearance of this paper Spiller and Frazier published an article ${ }^{8}$ in which they collected, under the term "cerebral decompression," a long list of early cases in which exploratory operations for brain tumors had been followed by symptomatic benefit to the patient, even though the tumor was not found or removed, and these were spoken of as decompression operations. It must be clear to all that experiences of this kind were the forerunner of the decompression idea, and the possibility of palliation as the unlooked-for result of an exploration had been expressed by no one more concisely than by Robert F. Weir ${ }^{8}$ as early as 1888 ; as follows:

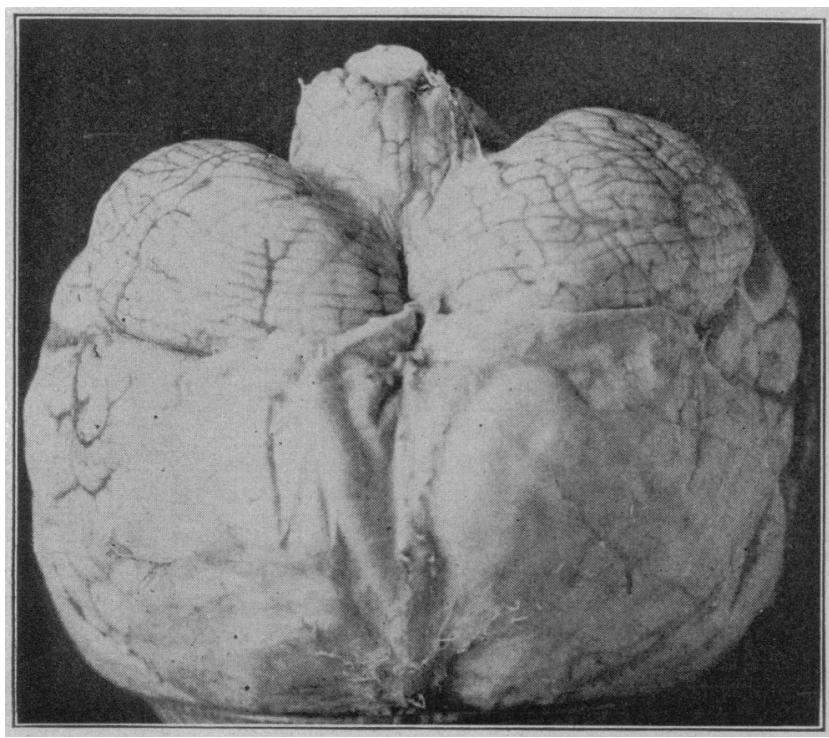

Fig. 13.-Photograph of posterior aspect of brain (Inverted) in which multiple tuberculomas were present in the left hemisphere and cerebellum, and in which death resulted from lumbar puncture. Showing mould of cerebellomedullary bernia through foramen magnum.

"One instructive point has appeared in connection with a case of my own, which is that though no tumor was found the patient's symptoms were materially improved from the relief afforded by taking away a goodly portion of the bone. The result may afford an additional reason for the justification of an exploratory operation, since if no tumor be found relief to the brain pressure can be at least temporarily obtained."

I particularly emphasized in my paper the fact that the operation which I proposed was conducted primarily for the purpose of relieving tension in cases of unlocalizable or inoperable tumors, and not that any craniectomy originally undertaken for exploratory purposes might in the end serve the purpose of relieving tensiona matter that had long been appreciated, as the quotation above indicates.

What I would wish again to lay stress on are the following facts:

8. Cerebral Decompression. Palliatlve Operations in the Treat ment of Tumors of the Brain Based on the Observation of Fourteen Cases, Unip. Penna. Med. Bull., 1906. xix, 146; also THE Journal A. M. A., Sept. 1, 1906, 679 ; Sept. 8, 1906, 744; Sept. $15,1906,849$; Sept. $22,1906,923$.

9. Weir and Sequin: Contribution to the Diagnosis and Surgical Treatment of Tumors of the Cerebrum, Amer. Jour. Med. Sci., 1888, xcri, 227-228.
1. The operation is conducted through a split-muscle incision which exposes the thinnest and most easily removed area of the cranial vault.

2. The exposed area of the brain is a "silent" area, the possible permanent damage to which in consequence of a forcible protrusion leaves no appreciable symptoms.

3. An undue protrusion is obviated by the protection of the resutured muscle, fascia and galea (Fig. 5).

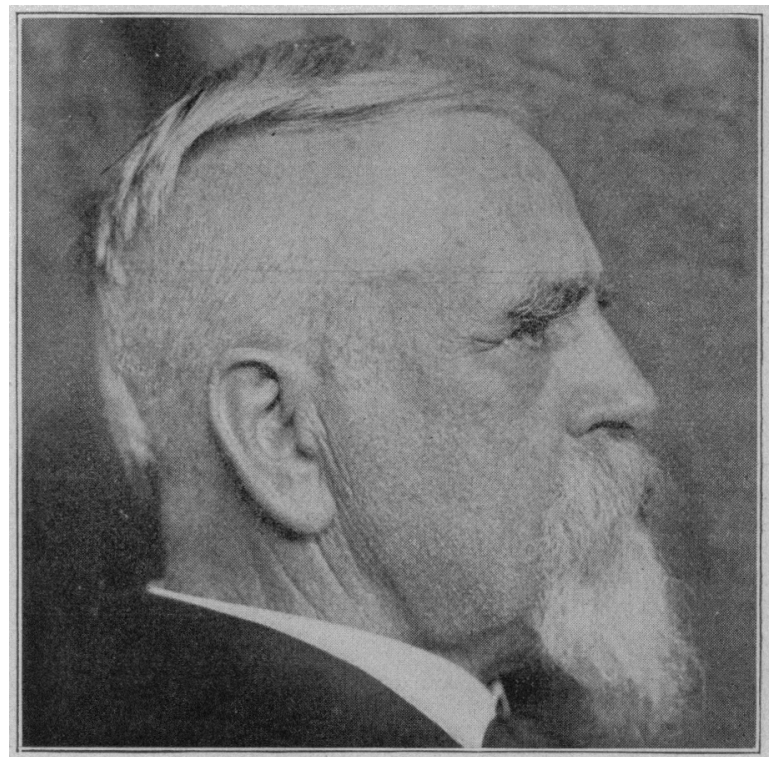

Fig. 14.-Photograph of patient elght days after a Gasserian ganglion operation to show llmits of incision, which are here clearly apparent; also partial shaving of hegd

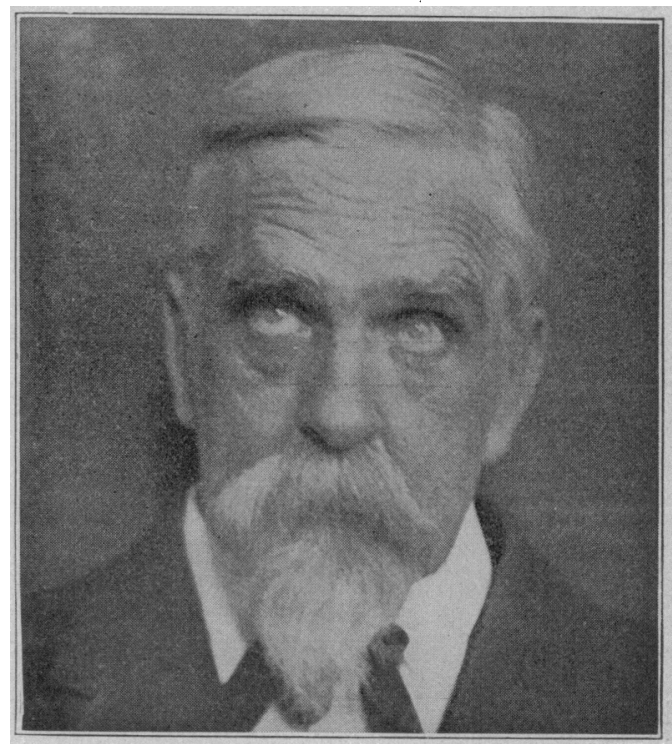

Fig. 15.- Same as Fig. 14, to show symmetrical wrinkling of brow and absence of other deforming consequences of the olde operative methods.

4. Except in case of a growth so placed as to produce an internal hydrocephalus (Figs. 10, 11, 12, and 13). usually a considerable, often a complete, subsidence of symptoms may occur.

I have spoken elsewhere of the undesirability of decompression over the presumed seat of a tumor, for the consequent dislocation of the parts, from protrusion of the brain, often leads to hemorrhage into or around a vascular growth, which greatly augments its size and may lead to an enormous hernia (Fig. 6). In other 
words, an exploratory operation turned into a palliative or decompressive measure may be disastrous.

The subtemporal decompression is purposely made in a situation away from the growth and is not only, I think, the most desirable procedure for cases of tumor which present no localizing symptoms, but during the past year the measure has been used as a preliminary operation for the temporary relief of severe pressure symptoms, even when the location of the growth is evident and gives promise of being accessible at a later operation.

On a few occasions it has been possible through such a rreliminary subtemporal decompression to preserve the osteoplastic flap raised at the subsequent operation for removal of the growth. Had the osteoplastic exploration constituted the primary operation, closure of the scalp would have been impossible without removal of the bone, and large defects of this kind in unprolected areas (that is, other than subtemporal or sub.

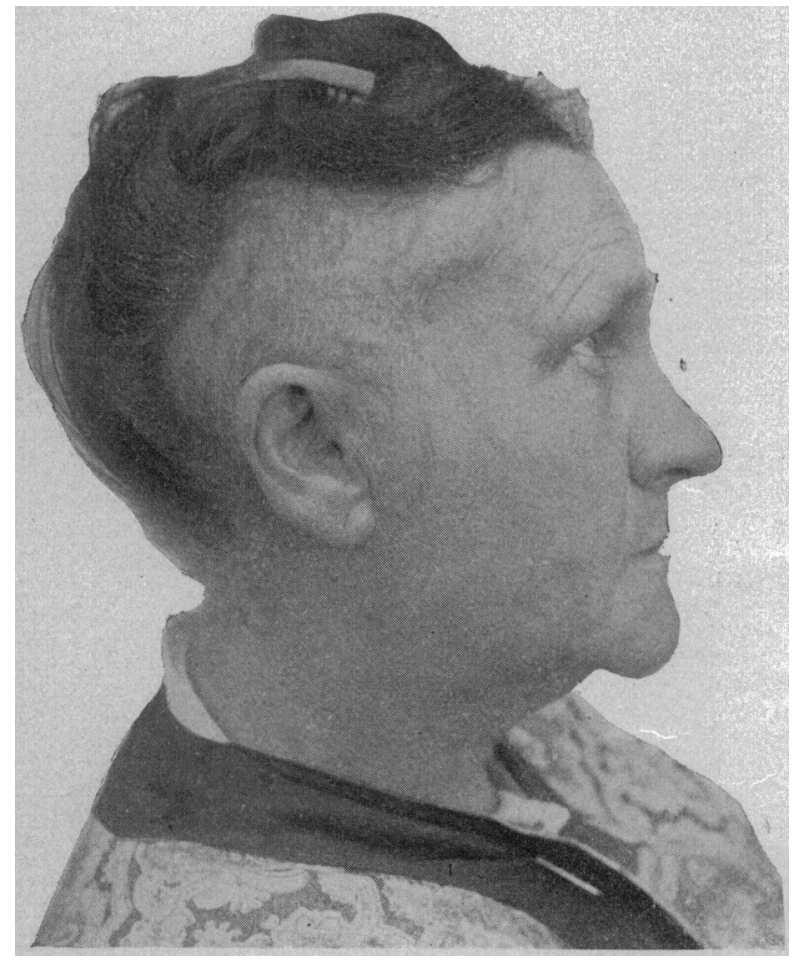

Fig. 16.-Photograph of patient seven days after the Gasserian ganglion operation. Note the Invisible wound; the partial shaving of the head; the preserved action of the occipito-frontalis muscle.

occipital ones) are distinctly undesirable, even though, as Horsley has shown, aside from the deformity they may lead to no serious consequences.

I have stated on another occasion that no brain tumor may be so favorable for prompt operation as one which gives absolutely no clinical indications of its situation. Though difficult to make clear to many neurologists, the significance of this seemingly paradoxical statement is explicable in the light of some of our more recent experiences. For a number of years (the first subtemporal decompression was performed in September, 1903) these decompression operations have become a more or less routine measure in certain cases, unti] at the present time-taking the subtemporal operations alone-there have been about 100 all told, 60 of them for presumed supratentorial tumors. Though many of these patients remain comparatively free from all symptoms of pressure, what is more important, others have returned after periods varying from one to three years with an onset of symptoms pointing at last toward the situation of the lesion, which in a number of instances has been successfully removed (Fig. 7).

In other words, the decompression in a safe area has usually so relieved the general pressure symptoms as to make patients subjectively comfortable and with their eyesight retained-a considerabe number of them indeed capable of earning their livelihood. Of the cases in which the growth has not been localized at the time of decompression, in some it has emerged, as it were, from its silent area and has shown focal symptoms; in others it has remained silent and in some instances indeed may even have metamorphosed into a cyst. Few of these patients would, I believe, have continued to live more than a few weeks or months, and some of them have passed from an actual bedridden state to active life again.

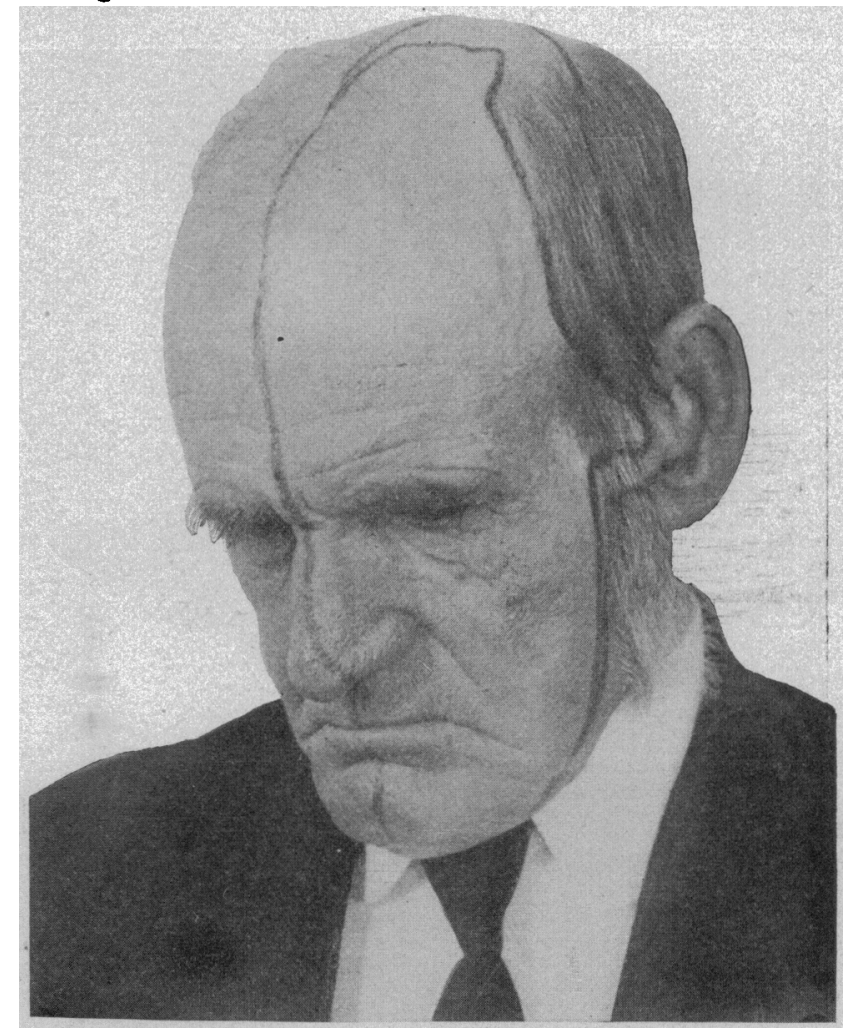

Fig. 17.- Showing persisting area of total anesthesia three years after a ganglion extirpation.

[At this point a number of lantern slides were shown, illustrating the steps of a subtemporal decompressive operation and of patients on whom the measure had been carried out, not only to relieve the increased tension of tumor but for other conditions associated with pressure, such as uremia and the cerebral edema accompanying basal fractures, cerebral arteriosclerosis, thrombosis and embolism of the cerebral vessels, etc.-Ev.]

\section{LUMBAR PUNCTURE IN BRAIN TUMOR CASES}

A brain tumor usually, though not invariably, increases the cerebral tension, causing thereby the underlying pressure symptoms of headache, dizriness, nausea or vomiting, and choked disk. This increase of cerebral tension leads, as we have seen, to a greater or less protrusion of exposed cortex through any operative defect which may have been made in the cranium and pachymeninx (Figs. 9, 10, 11, and 12). As is well known, Nature occasionally succeeds in relieving the tension 
made by a new growth-in the young through separation of the sutures, and occasionally in adult life, if the growth is a superficial one, by an area of pressure absorption. ${ }^{10}$

Furthermore a greater or less protrusion is inevitable through the normal opening at the foramen magnuma natural defect in the cranial chamber. As a result of this the brain stem with a surrounding fringe of cerebellum is crowded down into the spinal canal-a condition which is especially marked in the presence of a subtentorial growth; for the tentorium in a measure serves to protect the cerebellum and hind-brain from the pressure effects of supratentorial (cerebral) growths.

This protrusion of brain stem-an actual herria cerebelli-is of the utmost importance in its relation to the performance of lumbar puncture. For it is undoubtedly due to the presence of such a hernia that withdrawal of fluid by the lumbar meninges, especially in cases of cerebellar tumor, has so often been attended with early fatality from respiratory failure, the continued pressure from above sufficing, on the withdrawal of the fluid support from below, to further wedge the bulb into the foramen in such a way as to cause pressure anemia of the vital medullary centers.

Not a few instances of disaster in consequence of lumbar puncture have been recorded in the literature, and six have come under my personal observation-three of them were fatalities in the medical wards after puncture in cases of unsuspected cerebellar lesion, ${ }^{11}$ and three have occurred in my own surgical experience (Figs. 9, 10, 11, 12, and 13). If the brain after such an accident be removed from the cranial chamber soon after death, and particularly if hardened in situ, it will show the imprint of the foraminal ring about the protrusion which has been tightly jammed into the opening.

In Figure 13 the mould of this cerebello-medullary hernia is well shown in the brain from a patient with multiple cerebral tuberculomata - a single large tubercle in the left cerebellum having been unsuspected. During the course of a subtemporal decompression, owing to the great tension of the dura, a lumbar puncture was performed before opening this membrane. The fluid, under great tension, spurted for a monient from the needle, but ceased to flow after about 4 c.c. had escaped, when respiration almost immediately censed. Under artificial respiration the dura was quickly incised, and though for a few moments normal breathing was resumed it soon ceased and the heart continued to beat for three hours as an isolated organ, which doubtless could have becn kept in action under artificial respiration for a period indefinitely longer.

This is far from a unique experience, ${ }^{12}$ but it is cited lere for the purpose of emphasizing the hazard of lumbar puncture which exists in the presence of increased subtentorial tension.

In tumors above the tentorium, however, the continuous withdrawal of fluid during the course of an operation for decompression or for extirpation of a growth often proves an invaluable aid, and since I first caljed

10. It may be said that in most cases of increased pressure, minute hernix occur at the situation of the arachnoidal villa,
those that I have seen being particularly abundant over the under surface of the temporal lobes. Dr. S. B. Wolback has demonstrated that these minute surface irregularities are actual herniæ of the cortex. Journ. of Med. Research, July, 1908.

11. One of these cases was pictured and reported in the Mutter Lecture for 1901 (Am. Jour. Med. Scl., September, 1902, 398). Quincke has since called attention to this same process as out of the dangers of indiscriminate lumbar puncture, "Diseases of the the dangers of indiscriminate lumbar puncture, "Diseases of the Deutsche Klinik," D. Appleton \& Co., 1908, p. 233)

12. I have recorded another case with 24 hours of artiticial respiration, in my Mütter lecture, loc. cit. attention to the practice ${ }^{\mathbf{1 3}}$ it has frequently been employed. Helpful as the measure is and without particular risk, I believe, in solid lesions or edemas increasing the tension of the hemispheres, the possibility of an unsuspected cerebellar growth should always be borne in mind and the puncture not made unless the dura is exposed and ready for immediate opening in case medullary symptoms supervene.

In suboccipital explorations, on the other hand, the puncture would often be as dangerous as it is unnecessary, for one of the most important steps of these operations, after incision of the dura low down near the removed margin of the foramen magnum, is to open the exposed posterior cysterna and thus allow the pentup cerebrospinal fluid to escape from above. If this precaution is not carried out the cerebellar tension often causes the hemispheres to bulge through the first dural opening so markedly as to rupture the pia-arachnoid and thus to cause extravasations which of themselves, through edema, rapidly increase the tension already present.

\section{THE PRINCLPLE OF OUTWARD DISLOCATION}

This leads me to speak of the principle of dislocation without injury of normal cerebral or cerebellar tissue during an exploration or in the approach to a surface lesion more or less difficult of access, of which cerebellopontine tumors may be taken as a type. The thorough evacuation of cerebrospinal fluid from the basal cysternæ as mentioned above is of great assistance, but more important still is the bilateral opening with wide exposure of both cerebellar hemispheres. Under these circumstances, when one hemisphere is pressed to the side the other dislocates outward, giving a free view of the lateral recess without contusion of the easily damaged cerebellar tissue and without the field being obscured through blood staining. The latter is inevitable when a portion of the hemisphere is removed in order to give access to a tumor situated in this freely accessible angle. With a unilateral opening an equally free exposure is dangerous, if not impossible, without excision of a portion of the cerebellum.

This same principle is applicable to growths difficult of access in other situations, and I have found that in certain cases a preliminary subtemporal craniectomy, made some weeks or months before, proves sufficient for purposes of dislocation at a subsequent extirpation. For the approach to basal tumors in or near the midline I have occasionally made a large flap, with a wide dural opening, on the same side as that of the proposed exploration, and this has proved sufficient for thorough exposure in some cases, notably one of uncinate gyrus tumor and another of growth near the angular gyrus.

By applying this same principle I am confident that the best approach can be made to the pituitary body, though in these operations a bilateral opening is doubtless preferable-namely, a large exposure of the brain on the side opposite to that through which the pituitary fossa is to be exposed and a lesser cranial opening on the side of approach itself, with the smallest and lowest possible linear incision of dura. In this way the resistent membrane serves to protect the temporal lobe during its subsequent elevation, and through the large opening over the opposite hemisphere the brain readily dislocates outward in correspondence with the degree of

13. Technical Methods of Performing Certain Cranial Operations. Surg., Gyı, and Obstet., March, 1908, 237. 
elevation exerted during the approach to the hypophysis below the contralateral hemisphere.

Dr. Lewis L. Reford and I have found that this method of Paulesco's, with some minor modifications of our own, is a most ideal way of exposing the pituitary body, at least in dogs. ${ }^{14}$ We have found too in corroboration of his experiments that the hypophysis is essential to life-a clean, simple, bloodless extirpation, if total, being followed by death in about 48 hours. To the loss of just what one of the three portions of the gland, which Schäfer and Herring have described, this is due, we are as yet unaware, but the knowledge is enough to call a halt for the time being in attempted hypophyseal extirpations for tumor. It is the case of the thyroid and myxelema, the parathyroid and tetany, over again.

\section{GASSERIAN GANGLION OPERATIONS}

In some intracranial operations, however, the definito indications and necessary technical methods are well established-in no operation more definitely than that for trigeminal neuralgia of the major form. Here, although a certain amount of pressure against the temporal lobe is essential to a perfect exposure of the ganglion, this pressure is made against a brain not already under tension, as when a tumor is present, but against one susceptible of a certain amount of compression: hence in these operations the principle of dislocation need not be taken into account.

There is an element of danger, however, in too great pressure, and I think it can not be questioned but that the high temporal operation, so courageously originated some years ago by Hartley and Krause, entails more risk on this score than the more recent and lower methods of approach.

The degree of compression can be estimated if a carcful chart of the pulse-rate be kept during the operation, for the vagus effect, shown by a retardation of pulscrate, is proportionate to the degree of pressure-transmission against the medulla. In my earlier cases a pulse-rate as low as 60 per minute was not infrequent during the progress of the manipulations: this, however, has not occurred of late, doubtless through the experience gained in carrying out the enucleation through a very low and shallow opening.

Krause a year ago reported seven deaths in his series of 51 operations, and in all the fatal cases contusion of the temporal lobe was found postmortem-an evidence, I think, of the undue elevation necessitated by the high method of approach. I am able at the present time to report 74 ganglion operations, with only two deathsboth of the fatalities having occurred early in the serics at a time when the effort was invariably made toward complete enuclcation.

At present, the procedure is greatly simplified by the arulsion from the pons of the sensory root alone, the ganglion being left in its bed with a half-inch gap between its posterior border and its original pontine at tachment-a space which, even granting the possibility of central regeneration, could hardly be bridged by a now nerve. I think the method is preferable to the simple section of the nerve as proposed by Spiller and

\footnotetext{
14. Technical experience with difficult procedures such as thi (and I may include the ganglion operation) (an be acquired in no way so satisfactorily as by practice on living animals. Although the mere anatomic relations must be learned on the human cadaro before the operation can be transferred to man, nevertheless the ex perience of handling the central nervous tissues, of stopping bleed ing from bone, membranes and brain, can be and should be acquired on the lower aumals.
}

Frazier, not only for the reason given above, but also because it is possible to hook out the sensory foot intact, even in the many cases in which it is difficult or impossible to bring the structure sufficiently well into view to justify its actual division.

In the approach to the ganglion the incision (Fig. 14) should be so placed as to avoid (Fig. 15) the obtrusive droop of the brow which was an unavoidable consequence of the older methods owing to unilateral paralysis of the frontalis muscle. Similarly a careful closure of temporal muscle, fascia, ant galea aponeurotica, can entirely prevent the objectionable flattening of the temporal region in consequence of atrophy of the muscle. Often the incision may be absolutely invisible a day or so after the sutures are removed (Fig. 16). The area of anesthesia remains permanent (Fig. 1\%); and the return of sensation to the forehead, or its retention there wholly or in part after the operation, indicates only a partial success and a possibility of return of pain in the ophthalmic division. There is no authentic case of recurrence of neuralgia after total extirpation or complete removal of the sensory root.

In all surgery I know of no more satisfactory measure than a successful ganglion operation nor of one which more certainly and more permanently relieves a larger measure of incapacitating pain. However, no one should attempt these operations who has not seen to the education of his own and his assisant's reflexes to the highest possible degree in the performance of every particular step by operations on animals and by constant and repeated practice on the cadaver. Otherwise it is much safer for him to cling to the methods of temporary relief through peripheral operations, whether they be restricted to the injection into the nerves of mordants or to the removal of such of the branches as can be with. drawn without leaving the patient's face scarredsomething the ganglion operation does not, or should not, do.

\section{SUMMARY}

I have attempted to elucidate some matters in regard to a branch of surgery which in its present formative stage can only be safely undertaken with the best possible understanding of neurology. The few technical points which I have chosen to emphasize are:

1. The continuous auscultation of the heart-beat and respiration during anesthesia.

2. The subtemporal decompressive operation as an early measure and a step preliminary to a possible subsequent tumor extirpation.

3. The dangers of lumbar puncture in the presence of a degree of subtentorial pressure sufficient to produce a cerebello-medullary foraminal hernia.

4. The value of a continuous lumbar drain during the course of explorations for lesions of the hemispheres.

5 . The principle of outward dislocation of norrnal tissue to avoid the risks of compression or mutilation during deep explorations.

6 . The satisfaction of such intracranial procedures as the ganglion operation for trigeminal neuralgia whin once they are put on a basis of comparative safety.

\section{ABSTRACT OF DISCUSSION}

ON PAPERS OF DRS. CUSHING, HARTLEY, M'KERNON AND COAKLEY *

Dr. JoIr B. MURPhY, Chicago: The important lesson all of these papers bring to us is that there is here a splendid fied for excellent work, to be explored by trained hands, and

\footnotetext{
* The papers of Drs. Hartley, McKernon and Coakley appeared
} in THe Joukxil last week. 
that no other should attempt it. I wish to call attention to a few matters uneonnected with the technic of these operations. The ligature is splendid for the control of hemorrhage. Jigation of the external carotid can be accomplished in a few seconds, and in one condition particularly this ligation has been neglected for a great many years at a great life cost, and that is in hemorrhage from the middle meningeal artery. The general practitioner who does not do much surgery can ligate the external carotid artery the moment he notes the first symp toms of hemorrhage of the middle meningeal artery. These symptoms are so clear-cut that the diagnosis can readily be made. One does not have to hurry with the intracranial oper. ation or do it under unfavorable conditions, because after ligation of the external carotid artery one can do the operation when the patient is in a favorable condition for the removal or relief of the compression. An instrument devised by Dr. Neff is arranged to fit itself to any depth of cranium. It is an ordinary revolving drill and can be directed in any line desired. It does very good work. I have found no very satisfactory machine for cutting the eranium.

The small size of the flap has hampered operations of this kind. That was brought out by Drs. Cushing and Hartley, showing that we may have a large-sized flap, but we must not have a profuse hemorrhage, because that is the greatest danger in all of these operations. The next important matter referred to was the palpation and examination of the brain after the dura mater had been opened. The experienced hand frequently can locate an encapsulated tumor or cyst. We have devised a double needle which has a blunt probe end and an

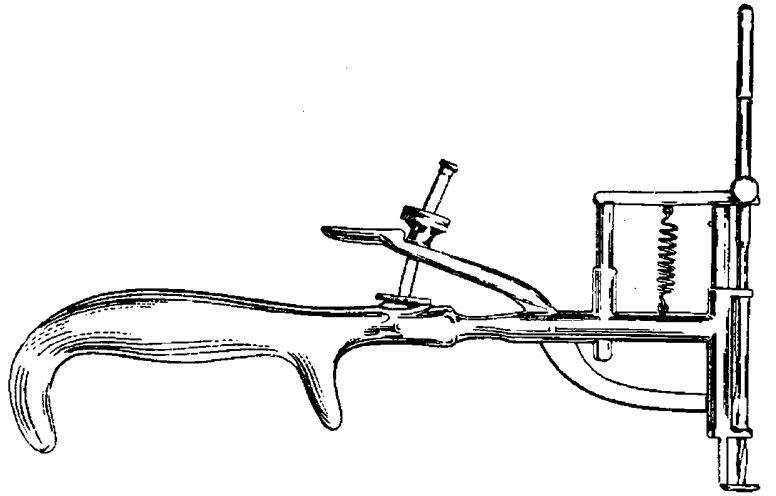

Farly model of cranial drill devised by Dr. Neff, referred to by Dr. Murphy.

opening so that when it is withdrawn one-sixteenth of an inch the lumen of the needls is opened and the contents of the cyst can easily be withdrawn. By keeping the opening closed until the capsule is punctured it is easy to withdraw any fluid.

Another practical matter is the advantage of the peripheral sacral cistern in drainage. In the infections with accumula. tions in the cerebrospinal tract you can avail yourself of the large sacral cistern or of the cerebellar eistern for the relief of pressure. The significance of the closure of the foramen of Majendie lies in the production of atrophy of the optic nerve central hydrocephalus without peripheral hydrocephalus; if that continues optic atrophy always results and persists be. cause regeneration is impossible. This operation I performed in 1896 , by opening and establishing a communication between the central and peripheral cisterns. In the central compres sions of the optic nerve it was found that the re-establishment of this opening would prevent atrophy of that nerve. I paid a very severe price recently in operating on a case of ependy mal spina bificla with paralysis of the lower extremity. The foramen of Majendie unfortunately was closed. I noticed that the child had central accumulation in the ventricles, but $I$ felt that the foramen of Majendie was open and $I$ permitted the patient to return home. To my horror and surprise, within six weeks, I was notified that vision had entirely disappeared There was a central accumulation and a complete atrophy before I was notified, when I could have easily-it is not a difficult operation-have resected a $\mathrm{V}$-shaped piece of the velum.
Dr. A. Jaxsex, Berlin: Like Dr. Coakley, T have seen very few cases of cerebral complication. In my observation of abour S00 operations on accessory sinuses I saw three patients, on whom operation had not been done, with purulent meningitis, and about 6 cases of large extradural abscesses. There was no case of brain abscess, and only one of a severe serous encephalomeningitis with unconsciousness, lasting several days. The result was recovery after a purulent focus in the posterior ethmoidal cells, near the optic foramen, had been emptied. When an operation is indicated on account of suppuration of the accessory sinuses, I have little fear of cerebral complications. This comes into consideration only when there is severe pain and other indications of retention of pus. I should like to call attention to the importance of serous meningitis and encephalomeningitis in their relation to purulent meningitis, and also to the fact that that purulent meningitis has been cured in a number of cases. Finally, I desire to call attention to the importance of the disturbances caused by cerebral complications affecting the vestibularis, appearing as disease of the nerve, basis or central organ (Deiters' nucleus). Tlie principal lesions to be taken into consideration are abscess of the cerebellum or tumor of the auditory nerve. The complication of tumor of the auritory nerve with purulent labyrinthitis is especially hard to diagnose. In several such cases, lumbar puncture showed pneumococei in the fluid. The postmortem in one ease showed an inoperable tumor of the anditory nerve, which had destroyed the cerebellum as far as the fourth ventricle. Nystagmus varies according to whether the peripheral end organ, the nerve, or the central organ is attacked. In the affection of the end organ, nystagmus is directed toward the healthy side of the head. In my case of tumor of the auditory nerve and in several abscesses of the cerebellum, it was directed toward both sides, but it varied. In looking toward the diseased side, the excursions were very extensive but infrequent: but in looking toward the healthy side the movements were very quick and minute. These differences seem to me to be of value in the diagnosis of tumor of the auditory nerve and suppuration of the labyrinth.

Dr. $Y$. J. BAccus, Chicago: Since asepsis in the cranial region is even more important than in the abdominal cavity, attempts have been made to secure a perfect aseptic isolation of the operative field. Long ago Fenger and Murphy, while operating on the head, isolated the field of operation by carry. ing the rest of the aseptic sheet over the anesthetizer. In the lantern-slide demonstration of operative technic on the skull shown here, no provision was made to isolate the head from the nose and mouth of the patient and the masks and hands of the anesthetizer. This can readily be accomplished by encircling the head with the aseptic sheet and resting it on ver. tical table supports. The next important factor in explora. tory operation on the cranium is to make a large flap. The ligation of the external carotid as recommended by Dr. Murphy need not be applied to all cases of skull surgery, as a romitine procedure. According to statistics, the majority of surgeons do not ligate the external carotid artery as a preliminary step. When there is a possibility of injury to the middle meningeal artery, as in operating for the removal of the Gasserian ganglion, it may be necessary to resort to liga. tion of the external carotid.

J)R. RoBert F. WeIn, New York: Those of you who have lived long enough will, perhaps, remember the birth of modern brain surgery. In 1875-80, thanks to the urgent encouragement of some of my friends in neurologic practice, I was led to enter on this field. It was not a long invasion, because it dawned on me early that $I$ was attacking tumors of the brain, most of which were malignant or which were local manifestations of a severe general disorder, such as tuberculo. sis and cancer. I learned soon that I was doing a very dangerous operation, and that I could give the patient only a comparatively short prolongation of life. It discouraged me, 1 admit. Also the results in connection with epilepsy were not very satisfactory as operations were then done. My zeal was not, however, quenched, and I entered on the work in other directions, such as entering the substance of the brain in cases of deep hemorrhages, or exposing by lifting up the brain en masse for traumatic hemorrhage at its base on one or both 
sides, or removing large surfaces of bone for the purpose of reaching and draining a suppurative meningitis. The great discouragement, however, I met brought me to the termination of my "brain" career and my enthusiasm departed and led me to go in other surgical directions.

As the outcome of my short experience, running over five or six years, three things of value have remained up to the present time. These have been alluded to in the admirable papers presented here to-day. The first was the rubber band around the head. We tried many ways to stop the annoying hemorrhage from the scalp. The rubber band I first resorted to at the suggestion of Dr. M. Allen Starr and it proved of such value as to retain its place in surgery. The second thing was the use of celluloid plates to fill in defects in the skull where bone had been destroyed by earlier operations, such as by multiple trephining or by grooving or by chiseling. I resorted to the use of these plates, perforated or non-perforated, also in fractures as well as in the brain tumor operations. following the example of the German surgeon, Fraenkel, and found their use very satisfactory. In one instance I kept track for five years of a patient in whom it was inserted for a large opening in the skull and found no disturbance arising from its retention. Dr. Cushing has alluded to the outcome of our experience of two unsuceessful attempts to find the tumor after a cerebral exposure. We succeeded here to an unexpected degree, however, in relieving the patient of distressing symptoms and advised then that such a procedure should be carried out in subsequent cases, which has been done to a large extent in recent years.

Dr. Willy MeYer, New York: On the basis of personal experience $I$ favor proceeding in the same way in the posterior fossa of the skull as in other parts of the skull, namely, by arranging for an easy access to the brain by a wide removal of bone--wider than is usually advocated. It has been advised that operation for tumor of the occipital region be done in two stages, also that access to it, especially to those tumors situated at the ponto-cerebellar angle, be gained by partial or total removal of the respective cerebellar hemisphere. This advice, it seems to me, should not be accepted without thorough discussion. A number of such operations in two stages are on record in which the patients died shortly after the bone operation had been completed, and the tumor was never exposed. In the interest of asepsis, it seems to me, we should try to get through with the work in one sitting. Furthermore, it stands to reason that, if we can accomplish our aim with the cerebellum left intaet, this must mean a gain to the patient.

With these points in view, and inspired by the excellent work of Cushing, Hartley and Frazier on this side of the Atlantic and of Krause abroad, I recently undertook an operation for tumor of the left auditory nerve in a girl, 27 years old. I do not think that osteoplastic operation can ever be done to advantage in this region, mainly on account of our inability to control hemorrhage properly, which, as is well known to those familiar with this kind of work, may prove alarming at times. ( $I$ would mention parenthetically that I have found Horsley's wax of great help in controlling hemorrhage in these cases.) Therefore, after having formed and turned down a large horseshoe-shaped skin-muscle-periosteal flap, and, according to Cushing, dividing it in the middle, I removed the entire occipital bone, first thinning it with a grooved chisel, then biting it with rongeur forceps. Of course, J carefully avoided the external occipital protuberance. The border of the foramen occipitale magnum was fully exposed. Then followed double ligature and division of the longitudinal sinus, heart-shaped incision of the dura mater and turning down of the flap. Now the entire cerebellum was before our eyes. With the help of a long brain spatula $I$ reached the internal auditory foramen and, with the electric reflector, clearly saw the tumor, of the size of a small hickory nut, involving the auditory and facial nerves. This was bluntly removed. Acute edema of the brain prevented the proper return of the dura mater flap. The latter just sufficed to cover somewhat more than the lower half of the cerebellum. Injury to the exposed brain from the irregular, roughened occipital protuberance was carefully guarded against by gauze tamponade. The skin flap was sutured in place. The patient made a good recovery. Having been almost totally blind before operation, with staggering gait and all the other symptoms of brain tumor, she is now able to read almost the smallest print. Her gait is improving steadily; she has done some needlework within the last few weeks, and we may now hope that she will go on to complete recovery. This case shows that easy access to the cerebellum obtained by the removal of a large piece of bone enables us to avoid pressure injury to the medulla or pons and renders unnecessary the removal of portions of the cerebellar hemisphere.

Dr. Harvey Cushina, New York: Widely different operative methods have been advocated in this morning's session by the different speakers-methods which have the same end in view, namely, the most rapid way of entering the skull compatible with perfect safety. It goes to show partly that the individual needs of one operator are not necessarily those of another, and partly that familiarity with a given set of instruments breeds facility in their use. After all, the best osteoplastic method of exploration is chiefly a matter of technical interest. What those of us who are interested in neurologic surgery are trying to do is not so much to perfect methods of rapidly laying bare the surface of the brain as to perfect our ability to diagnose a cerebral lesion and to evolve the proper methods of dealing with it when once the skull has been opened. We are only at the beginning of these matters, though strides forward are being made daily by the Ieaders in this work. It does not make any difference whether the bone flap is turned down by one method or anotherprovided, indeed, a bone flap is necessary, and often in fact it is not. It is what is to be done on the inside that is vital, and for this some knowledge of neurology is absolutely necessary; and that is the plea I wish to make to-day-the necessity of a neurologic training for those who wish to follow this particular kind of work.

Dr. Weir's contributions to this field of surgery made twenty years ago are well known to all who have made themselves familiar with the early literature of the new cerebral surgery; but I think that he is a little too optimistic about some of these present endeavors of ours, and Dr. Murphy's unbounded enthusiasm must not make us go too fast. Thus, his anticipation of twenty-five extirpations of the pituitary body within the next year, if they are "successful," or, in other words, total, means unquestionably twenty-five deaths in the twentyfive cases, for recent work has shown that the pituitary body - or I may say a portion of the pituitary body-is absolutely essential to life.

Dr. Frank Hartley, New York: Two things of importance for the next year are the production of instruments which can be used by every one and of a simpler means of stopping hemorrhage. The various saws and drills which are used now, and which are necessary to do rapid work, require a long period of tuition before one can use them safely. Therefore, I think that it would be a great advantage to have, in the first place, instruments which could be used by any one with perfect ease and safety. In the second place, I think that the thing which will advance cerebral surgery more than any other will be some simple method of stopping hemorrhage. As soon as we stop the hemorrhage, we diminish the shock; when we diminish the shock and stop the hemorrhage, we can spend a time in enucleating the growth from the cerebellum or cerebrum or whatever point we are trying to reach.

Dr. Chardes H. Frazier, Philadelphia: I feel very much as Dr. Cushing does about the development of cranial surgery. We are just making a beginning again in this field, it seems to me, after the setback which the work received at the hands of the German surgeons, notably von Bergmann, not many years ago. We have accomplished certain things, such as tho development, I might almost say perfection, of the technic of exploratory operations for lesions anterior to the tentorium cerebelli, and the technic of operations on the Gasserian ganglion. As to operations for lesions posterior to the tentorium cerebelli the technic seems to me in many ways deficient. We have not, as Dr. Hartley pointed out, discovered a way of adequately controlling hemorrhage, and, no matter what efforts 
we make, hemorrhage may be so profuse as to become alarm. ing in a few minutes after the operation has been begun.

We have heard nothing to-day of the two-stage feature of cranial operations, and I take it that it has been very largely abandoned, and, I think, properly so. By means of bloodpressure observations we can determine with reasonable accuracy the condition of the patient, and there is no reason why, once the tumor or lesion has been exposed, we should not at once proceed to its removal. The dangers of infection from reopening the wound and of a second anesthetization are so great as to make the two-stage operation absolutely unjustifiable. The decompressive operation has become so popular of late that there is a danger of its adoption in cases in which an exploratory operation is clearly indicated. Although decompression entails less risk to the patient, it is less difficult and requires less experience. When there is the least suspicion of the presence and location of a lesion, it is the surgeon's duty first to explore the region under suspicion; failing to find it, he may then conclude the operation with the removal of as much of the dura and bone as may be necessary to effect decompression. If this course is not adopted, many operable lesions will be overlooked and the percentage of absolute recoveries proportionately decreased.

Dr. C. G. CoAkley, New York: I did not go into the matter of deatls following operation at all. I merely spoke of the cases of sinus disease which in the last few years were almost invariably fatal because no operation was done; but the tendency now is to operate and a certain proportion of these patients will recover that would have died.

\section{DECAPSULATION OF THE KIDNEYS FOR CHRONIC BRIGHT'S DISEASE}

WITH A REPORT OF THE RESULTS, IMMEDIATE AND REMOTW, OBTAINED IN 102 CASES THUS TREATED *

\section{GEORGE M. EDEBOHLS, M.D.}

NEW YORK

When, in 1901, I suggested treating chronic Bright's disease by decapsulation of the kidney's, I placed myself under a moral obligation to report the results after a sufficient length of time had elapsed. In fulfilment of this obligation the present report is submitted:

The working theory on which I based my procedure of renal decapsulation for chronic Bright's disease was that by the removal of the impervious capsule an opportunity was created for the formation of new vascular connections between the blood vessels supplying the secreting structures of the kidney on the one hand and the blood vessels and tissues surrounding the kidney on the other. An additional blood supply is thus created for the kidney. The increased blood supply and activity of circulation are depended on to improve the working coefficient and gradually to restore the health of the kidney.

My observations on the kidneys of some of my patients who have died months and years after decapsulation, or whose kidneys I have decapsulated a second-and in one instance a third--time, have invariably demonstrated the formation of a more or less abundant new blood supply as the result of operation. While the creation of a new blood supply to the kidney readily explains the clinically established fact of eontinued and lasting improvement in the work of a diseased kidney after decapsulation, it fails to explain fully

* Owing to the illness of the late Dr. Edebohls, which prevented his attendance at the Section on Surgery and Anatomy of the American Jedical Association, Fifty-ninth Annual Session, Chicauo, Amer June, 1908. this paper was read by Tr. Samuel Lloyd. Because of the elaborate bibliography which appears in the Transactions of the elaborate bibliography which appea
the section and.in the author's reprints. and satisfactorily the immediate beneficial effects so often witnessed. I have never in any of my operations for chronic Bright's disease found the capsule tightly stretched and compressing the kidney. Generally it fits the kidney, and sometimes the kidney even appears to be somewhat shrivelled or contracted within the lonsely fitting capsule. Even in far-advanced chronic interstitial nephritis with greatly thickened capsule, the reduction in size of the kidney appear's to be due rather to contraction of the new fibrous interstitial tissue of the kidney itself than to compression of the capsule. I believe that the immediate good effects of decapsulation can be explained by the necessary manipulation, amounting in reality to a massage of the kidney, during operation. The immediate stimulation of the existing blood supply of the kidney thus effected, supplemented by the relief to congestion afforded by the direct abstraction of more or less blood from the organ during operation, suffices for the immediate needs of the kidney and carries it along until its supplementary new circulation becomes established. If we can cure chronic Bright's disease by renal decapsulation we can well afford to wait until time and further observation bring the explanation of the exact physiologic effects of the operation.

One invariable effect of renal decapsulation is the formation of a new capsule. This becomes distinctly organized in from three weeks to three months, is sometimes thicker, sometimes thinner, but always more succulent and vascular than the original. It has been suggested that this new capsule must inevitably contract and lead to injurious compression of the kidney with a return of the symptoms. This argument is not based on actual observation, nor is it in harmony with the results of animal experimentation, or with the clinical facts. I now give but little thought to the question of possible danger of contraction of the new rapsule. The immediate effect of decapsulation is to increase the daily output of urea and cause the disappearance or lessening of uremic manifestations. I have known a daily excretion of 6 grams or less of urea, prior to operation, to be increased to a steady output of 30 to 35 grams within a month after operation.

Renal decapsulation onables any given kidney to do the best work which it is possible for that particular kidney to do. I now decapsulate every kidney operated on for any purpose, and believe that the nther kidney should be explored and decapsulated before completing a nephrectomy. For the purposes of this report the diseases of the kidney are classified as: first. interstitial nephritis, those cases in which the gross evidences of inflammation of the connective tissne of the kidney predominate; second, parenchymatous nephritis, those in which the involvement of the secretory apparatus forms the salient feature; and, third, diffuse nephritis, those inflammations of the kidney characterized by implication in fairly equal degree of both the parenchyma and the connective tissue of the organ.

The diagnosis of chronic nephritis on the living subject is easy after some experience, the pathologic changes being more appreciable with the blood circulating through the kidney than they are after death. It is easy to recognize in the adherent capsule, nodulation, granular condition of the subcapsular surface, shrinking, unequal contraction, and oceasional cyst formation, a chronic interstitial nephritis; or by the enlargement, cloudy swelling, mottling, and discolorations due to 